\title{
Redefining Cantonese cuisine in post-Mao Guangzhou ${ }^{1}$
}

\author{
Jakob A. Klein \\ School of Oriental and African Studies \\ jk2@soas.ac.uk
}

\begin{abstract}
To what extent do regional cuisines provide a set of principles through which "outside" flavours, foodstuffs and techniques may be safely incorporated? This question is explored through an ethnographic account of Cantonese cuisine in Guangzhou (Canton) at the turn of the twenty-first century. I focus on a historic restaurant in the city, where managers and cooks sought to innovate with the help of "outside" tastes, but without the restaurant losing its status as a "traditional" establishment. I argue that the incorporation of "outside" flavours onto local menus was not done on the basis of culinary principles alone, but that considerations of social hierarchy and cultural identity were equally important factors. Indeed, many of the dishes and techniques introduced contradicted the alleged principles of Cantonese cuisine. Such contradictions were downplayed, however, through essentialized representations of Cantonese cuisine and its relationship to specific localities.
\end{abstract}

\section{Introduction}

The rapid proliferation of restaurants, teahouses and snack shops in Guangzhou (Canton) during the reform era of the 1980s and 1990s was hailed by local food scholars (e.g. Gao and Gong 1999) as a "revival" of the city's Cantonese cuisine and a "restoration" of the gastronomic reputation the city had enjoyed during the late Qing (1644-1911) and Republican (1912-49) years. ${ }^{2}$ This view was shared by people I met in Guangzhou in

1 This article draws primarily on my PhD research (Klein 2004), which was supported by an ESRC postgraduate research fellowship. Fieldwork was conducted in both Mandarin and Cantonese. In the text most Chinese terms are given in Mandarin, using pinyin. Cantonese terms are given only for colloquial sayings and terms with no direct Mandarin equivalents. Where Cantonese (C.) words and phrases are used, they are transliterated using the Yale system. Previous versions of this article were presented in January 2007 at the East Asian Research Society, University of Leeds and in February 2007 at the East Asian Institute, University of Cambridge. I would like to thank the organizers for inviting me and everyone who commented on my presentations. I would also like to thank two anonymous reviewers for their many helpful suggestions.

2 In 1972, Guangzhou had 512 registered eating and drinking establishments (Gao and Gong 1999: 61). By 1987, the figure had risen to 7,851 in the urban areas alone (Guangzhou 1988: 250). A decade later, the number of registered catering places in the now expanded urban areas had doubled to over 16,000 (Guangzhou 1999: 273). 
1999 and 2000, who sometimes claimed that there had been little or no "food culture" (yinshi wenhua) in the city during the revolutionary years of the 1950s, 60s and 70s. As one man explained to me over tea and snacks, "At that time there were not enough grain staples (zhushi)". Pointing at the dainty delicacies on the table he continued, "How could we think about supplementary foods (fushi)?"

Guangzhou's culinary revival did not occur in isolation from the wider world. From the beginning it was accompanied by - and arguably dependent upon - the arrival of goods, capital, ideas, people and skills from outside the city. In the 1980s, the most significant outside influence was undoubtedly that of Hong Kong, which had by then emerged as a metropolitan centre with its own distinctive brand of Cantonese cuisine (Tam 1997; 2002; Cheung 2002). By the mid-1990s, eating places offering dishes from Sichuan, Hunan, the north-east and other Chinese regions that had been sending migrants to Guangzhou since the mid-1980s had become well-established on Guangzhou's restaurant scene. In addition to Hong Kong style Cantonese cuisine and regional Chinese foods, the 1980s and 90 s also witnessed a growing number of establishments serving Western style and other foreign foods, including transnational fast food chains, locally owned and managed Western style cafes, Thai and Vietnamese places and exclusive Japanese and French restaurants.

To some people in the city this growing presence of outside cooking styles appeared to cause a degree of anxiety. Informants bemoaned the loss of what they saw as a greater culinary order in the past, when each urban area had its own distinctive and representative eating places, and when cooking techniques were properly handed down from master to apprentice. These days, I heard some say, youth are becoming increasingly "Westernized" and care little about correct methods. People know less about taste and health, it was argued, and care only about superficial things such as the romantic ambiance (qifen) in Western restaurants or the social status (shehui diwei) associated with consuming rare game. In other words, the pride in Guangzhou's culinary revival during the reform era was accompanied by fears that Cantonese cooking traditions were in fact being lost, and that Cantonese cuisine was losing its central role in the city's culinary life.

Elsewhere (Klein 2006), I have discussed how food journalists in the late 1990s attempted to guide Guangzhou consumers through the city's new found culinary diversity. Here I ask instead: To what extent and in what ways have "outside" tastes actually impacted on "local" cuisine? Was Guangzhou's culinary distinctiveness being overshadowed by the impact of foreign and regional cuisines or by that of Hong Kong style Cantonese cuisine? I will show that the "outside" impact on Cantonese cuisine in Guangzhou has indeed been considerable. By the turn of the twenty-first century a number of cooking techniques, dishes, foodstuffs, condiments, sauces and serving styles unheard of twenty years before had been adopted by the city's Cantonese restaurants.

This is not in itself surprising. As the historian of Japanese food culture, Katarzyna Cwiertka, has recently observed, "It goes without saying that 
cuisines are continually hybridising processes rather than fixed things" (2003: 92). Indeed, if we were to look at Cantonese cuisine historically, we might conclude that it has been profoundly shaped by centuries of migrations and trade flows, and that the emergence of Guangzhou's culinary renown in the late Qing or early Republican period was inseparable from its role as a hub of regional and global trade (Simoons 1991: 54-5, 513-15; Ye 1992). However, what I do find striking is the fact that despite this mixing and despite the anxieties about a loss of indigenous tradition and order, Cantonese cuisine was also frequently described to me in terms of an unchanging essence, a cuisine whose timeless principles distinguished it clearly both from foreign foods and from other regional or local Chinese cuisines. Rather than simply providing examples of the mixing of "local" foods with "outside" flavours, I explore what appears to be a paradoxical combination of rapid change and conservatism in food habits (Mintz 2002). Following Richard Wilk, I try to make sense of what he refers to as the "simultaneous processes of mixing and ordering" (2006a: 17) that typify "local" cuisines in the current phase of globalization.

In other words, what interests me here are the processes through which particular culinary combinations were achieved and the social meanings that people made of the results. Which techniques and tastes were adopted, and which were rejected? How did people arrive at these choices? Were they made entirely on the basis of cooking conventions, or were there nonculinary issues at play, such as considerations of social status and cultural identity? My account draws on ten months of ethnographic research on Guangzhou's teahouse and restaurant world conducted in 1999 and 2000. Much of the discussion focuses on my key fieldsite in the city, a multistoreyed teahouse-restaurant, which I call the Glorious China. With a history of over 100 years, the Glorious China was a self-styled "traditional" Cantonese establishment. It was locally renowned for having preserved traditional cooking techniques and specialities dating back to the Republican era, but it had also recently introduced a number of sauces, dishes and techniques from other regional and foreign cuisines. I should emphasize that my focus is on commercial cuisine. Changes in domestic cooking practices, and the relationship between domestic and commercial cuisine, are important areas for further research. ${ }^{3}$

\section{Cuisine}

One way in which the relationship between mixing and ordering has been thought about is through the concept of "cuisine" itself. For many anthropologists and historians of food, cuisine is a set of rules or principles for selecting, preparing, flavouring, serving and eating foods, and on some

3 Cheung (2002) suggests that in Hong Kong, people ate conservatively at home, and were more experimental when eating out. This is an interesting hypothesis that might be explored in Guangzhou. In the light of Short's (2006) point that arguments tend to be made about home cooking despite the lack of research, I will refrain from too much speculation in this piece. 
accounts also for producing foods and for relating food and eating to wider value systems (Cwiertka 2006: 11-12; Belasco 2004[1999]: 219-20). Scholars emphasize that these kinds of principles do not simply define what is edible and what is not, but also allow "cultures" to decide which "foreign" foods may be incorporated and how this may be done in such a way that transforms them into unthreatening, familiar fare (Rozin and Rozin 2005 [1981]; Ashkenazi and Jacob 2000).

While some present cuisine as an underlying, more-or-less subconscious and enduring logic (Chang 1977: 7; Rozin and Rozin 2005 [1981]; Ashkenazi and Jacob 2000), the anthropologist Sidney Mintz (1996: 92105; see also Sutton 2001: 110-15) emphasizes that people actively talk about food, and that this discourse about food is crucial to the maintenance of a cuisine, as it "sustains both common understandings and reliable production of the foods in question" (1996: 104). For Mintz, such discourse, common understandings and food production can really only work at the level of a region or locality. National cuisines, by contrast, he sees as artificial constructs, which appropriate ingredients, methods and dishes from different regions, and in doing so remove them from their social and economic moorings in specific regional communities. He writes:

[A] cuisine requires a population that eats that cuisine with sufficient frequency to consider themselves expert on it. They all believe, and care that they believe, that they know what it consists of, how it is made, and how it should taste. In short, a genuine cuisine has common social roots; it is the food of a community - albeit often a very large community (1996: 96).

I find Mintz's arguments that cuisine is socially grounded and that it is as much about talking as it is about eating or cooking extremely useful. However, his insistence that "genuine" cuisines are those of "regions" and "communities" begs the question of what those regions and communities are in the first place. "Regional" or "local" communities are no less sustained through imaginings and cultural inventions than are "national" ones (Anderson 1991; Hobsbawm and Ranger 1983; Cohen 1985). Anthropologists and historians have shown how food and eating have been a part of the production of such regional communities, often in ways that have simultaneously invoked and reworked specific national or transnational identities (Appadurai 1988; Csergo 1999; Avieli 2005; Chua and Rajah 2001).

This is not to argue that regional and national cuisines are both spurious. Rather, communities are imagined with the help of explicit symbols and performances, but these symbols produce enduring sentiments only insofar as they relate to people's experiences and ongoing social relations (Amit 2002). Indeed, one of the reasons why food is often such a powerful symbolic resource in the construction of communities may be its groundedness in experience and social relations, one aspect of which is its ability to evoke memories of shared meals (cf. Sutton 2001). Richard Wilk (2002) discusses two sides of food culture, which roughly correspond to the 
"symbolic" and the "experienced" aspects of community. On the one hand, he suggests, there are the daily practices of selecting, cooking and eating foods. On the other hand, there are the more self-conscious and public practices of naming, formalizing and performing that cuisine as a regional or national cuisine. It is not that one is more authentic or genuine than the other, but that, as Wilk argues, there is an ongoing interaction between the "performed" and the "lived" aspects of cuisine. ${ }^{4}$ A cuisine does not need to be named or formalized in order to be considered a cuisine, but it is difficult to imagine a regional or local cuisine in the contemporary world that is not both lived and performed. What makes food talk so important for maintaining a cuisine is not only that it is embedded in concrete practices and experiences, but also that it often involves a self-reflexive and performative element, a discussion about what "we" eat in contrast to "them" and - by extension - about who "we" and "they" are.

\section{Cantonese cuisine and identity}

An immediate problem one faces when considering Cantonese cuisine as a regional cuisine is defining what that region is. Depending on the context, "Cantonese" cuisine might be that of Guangzhou, or of Guangzhou and the Pearl River Delta area including Hong Kong and Macau, or of the Province of Guangdong, or that of Cantonese speakers in Guangdong and Guangxi, at times also including the foodways of Cantonese speakers in the diaspora. As we shall see later in the context of Guangzhou and Hong Kong cuisine, such distinctions could be maintained, but they could also be downplayed or denied.

In theory, moreover, one can distinguish Guangzhou cuisine (Guangzhou cai) from Guangdong cuisine (Yuecai, Guangdong cai), and food scholars tend to divide the latter into three main regional-culinary groups, roughly corresponding to the province's main dialect groups: Cantonese, Hakka and Chaozhou cuisines (Han 1992; Li 1995). In daily speech in Guangzhou, however, the words "Guangzhou cuisine" and "Guangdong cuisine" were used interchangeably, while Hakka and Chaozhou food were invariably talked about as separate from "Cantonese cuisine".

Despite the ambiguity of the term, in many ways Cantonese cuisine in Guangzhou fits neatly into Mintz's description of a genuine regional cuisine. There seemed to be a great number of shared understandings about food among my Cantonese-speaking interlocutors in the city. These had to do, for example, with the structure and proper etiquette of particular kinds of food events, including the notion that a meal consists of proper amounts of cooked grain (typically rice) on the one hand and supplementary side dishes on the other. There was also a widely shared language used to discuss the relationship between food and health, emphasizing in particular the humoral concepts of "heating" and "cooling" foods and the need to achieve a proper balance between the two.

4 In a more recent work, Wilk refers to the lived aspects of a "food culture" as "cooking", reserving the term "cuisine" for its public performance (2006b: 105-8). 
Other shared notions had to do with the ways in which different foodstuffs could be combined and the importance of freshness and seasonality when choosing and preparing ingredients. Some of these notions were of course shared with other Chinese. Others, in particular those that had to do with the selection, combination and preparation of ingredients, were more specific to the region or in some cases to the city. ${ }^{5}$ Popular sayings such as "Spring onions - raw, garlic - cooked, Chinese chives - half-done" (C. Sang chung suhk syuhn bun bihng gauchoi) instructed people on the "correct" use of condiments in Guangzhou cooking. Another Cantonese ditty I heard drew attention to the best time of the year for eating some of the different fish found in the Pearl River Delta area: "Spring bream, autumn carp, summer shad" (C. Cheun bin chau leih hah saamlaih).

Food was also an immensely popular discussion topic, even to the extent that outsiders from other parts of China complained that people in Guangdong were obsessed with food. "They don't talk about anything, all they talk about is food!" as one friend from Inner Mongolia put it to me. Conversations about, for example, the quality and prices of foodstuffs in the markets, or of the different delicacies served in local teahouses and restaurants, or about which foods to avoid when suffering from particular ailments, could be heard in many social settings.

One of the things that people talked about was the question of what it was that distinguished Cantonese cuisine and "Guangzhou people's tastes" from other Chinese regional cuisines. That this was not simply something people talked about in the presence of foreign anthropologists is suggested by the prevalence of the question in local dailies (Klein 2006), in essay collections by local writers (Shen 2000), and in popular histories of the city and region (Zhu 1999-2000; Deng et al. 1997). Although food was frequently articulated with "Cantoneseness" and "Guangzhou identity" in these writings and in everyday conversations, food was not the only marker of local or regional identity available to people in Guangzhou and the Pearl River Delta. Others included spoken and written forms of Cantonese (Snow 2004), Cantonese opera (Latham 1996), local festivals (Siu 2002), the region's role in the Republican revolution and in the history of the Chinese Communist Party, and pragmatic, down-to-earth yet also cosmopolitan and outward-looking attitudes supposedly grounded in the region's history as a centre of trade (Friedman 1994). As in the case of food, many of these practices and assumed character traits could be used to define identities at different levels, ranging from urban districts and specific Delta townships to Cantonese speakers throughout the world. Moreover, foodways were often articulated with other characteristics and cultural traditions. For instance, people from Guangzhou sometimes claimed to me that they had a "pragmatic" (shiji) approach to eating out, never ordering too much and insisting that leftovers be brought home. They contrasted themselves

5 For accounts of the basic principles associated with Chinese cuisine, see Chang (1977) and Sabban (1999). For Cantonese cuisine see Simoons (1991: 54-7) and Anderson (1988: 207-17). 
favourably in this respect to people from elsewhere in the country, who they regarded as wasteful, ostentatious and overly concerned with "face" (mianzi). I shall provide further examples of such articulations below.

Despite its significance at the turn of the twenty-first century, however, the uses of food as a marker of Guangzhou identity have changed over time and need to be understood in historical context. Thus, while late nineteenth- and early twentieth-century Guangzhou had a flourishing catering trade, and chefs from the region and Cantonese restaurants enjoyed fame in cities like Shanghai (Simoons 1991: 54-5; Goodman 1995: 22-3), it is not clear at what time people in Guangzhou actually developed a sense of sharing a common cuisine. Indeed, Michael Tsin (2000) has argued that there existed little or no common urban identity in late Qing Guangzhou, which came under the jurisdiction of two separate counties (xian), and whose massive city walls divided the "official" city of yamens and garrisons inside the walls from the heavily populated, and in some cases commercial, built-up areas outside them. ${ }^{6}$ Such an identity, Tsin contends, emerged only during the 1910s and 1920s, when the city became increasingly integrated in terms of administration, architecture, infrastructure and economy. New forms and sites of consumption and entertainment played an important part in this emerging urban identity (Tsin 2000: 25-8; Ho 1991), and it is probable that food and eating figured in it, too. Indeed, by the 1920 s and 30 s, the vibrant restaurant and teahouse scene in Guangzhou was being celebrated by visitors from Shanghai (Huang 1936) and Beijing (Wang 1927), as well as in official guidebooks to the city (Guangzhou 1934). More locally, Guangzhou's culinary status was vastly superior to that of Hong Kong (Faure 1996: 14; Tang 1999).

The Communist victory in 1949 had important implications for the question of cuisine and identity in Guangzhou. The new leaders were determined to transform Guangzhou from a centre of commerce and consumption to a hub of industrial production (Schintz 1989). Teahouses, restaurants and snack shops came under attack in political campaigns, particularly during the Cultural Revolution, as vestiges of the "Old Society". Thousands of eating establishments were closed down, as work units took on responsibilities for both communal dining, through the new system of canteens, and for organizing "leisure" activities on behalf of their members (Croll 1983: 231-4; Wang 1995).

Paradoxically, however, at certain moments during the "revolutionary years" of the 1950s, 60s and 70s, local cuisine was celebrated. The catering trade was nationalized and centralized during the second half of the 1950s, and became the basis of a culinary project. The project, part of a nationallevel programme aimed at defining and reforming Chinese cuisine and its

6 In contrast to Tsin, Steven B. Miles (2006) draws attention to the intense interaction between merchants and gentry in late Qing Guangzhou. He argues that, among the elites, there did emerge a shared "Guangzhou" identity over the course of the nineteenth century. This identity was pitted against that of the Pearl River Delta hinterland, and expressed through styles of scholarship and intellectual associations. However, it is unclear to what extent these "Guangzhou" and "Delta" identities were also shared by non-elites. 
regional components, involved researching and describing Cantonese cuisine from and also "massifying" (dazhonghua) it. "Massification" in this context meant partly that Cantonese cuisine was to be "reformed" to be more suitable to the revolutionary ideal of frugality. Cheaper, more readily available ingredients were to be substituted for the expensive, often imported ingredients on which Cantonese haute cuisine had relied, such as swallow's nests, shark fin, abalone and sea cucumber (Zhongguo 1976: 2 3). But "massification" also meant that previously elite restaurants were to offer banquets at prices affordable to ordinary residents (Liu 1999: 25-9), and that culinary knowledge and skills were to be widely disseminated to work unit canteens and homes. Through such measures, ordinary workers were to be able to enjoy the best of Guangzhou's delicacies which, it was claimed, had been denied to them in the "Old Society" (Zhongguo 1976: 2). The socialist culinary project included food expositions, the concentration of top-level chefs at chosen restaurants, and the publication of cookbooks. It also included plans to substitute the apprenticeship system for cooks with standardized cooking academies. Academies were not actually established in Guangzhou until the 1970s and 1980s, and even then training opportunities were limited (Gao and Gong 1999). ${ }^{7}$

Of course, few if any canteens lived up to the revolutionary ideals (Yan 2000: 208-10). Many foodstuffs were rationed in China's cities between the mid-1950s and mid-1980s, and much of the best dining in Guangzhou and elsewhere in the country was reserved for foreign visitors and for the new elite class of high-level officials (Hsu and Hsu 1977: 313; Davis 2000: 14). Nevertheless, the culinary project, which was pursued with renewed vigour in the early 1980s following the introduction of reforms, ensured that restaurant- and teahouse-going remained a part of popular culture in

7 Most cooks in the Glorious China, as in other state-owned establishments, had learned their trade through a combination of informal apprenticeships in the kitchen and formal schooling at academies. Indeed, it is not unlikely that cooks' understandings of Cantonese cuisine had been deeply influenced by the academy teachers and textbooks. Formal training usually consisted of short-term, intensive courses at the end of which they had to take both written and practical tests appropriate to the rank they were trying to achieve. Cooks in the Glorious China often expressed pride in their official rankings. However, they were also highly suspicious of cooking schools and theoretical training, and argued that Cantonese cooking could only really be learned through practice. Moreover, academy teachers were seen as conservative, teaching only old techniques and styles. They were regarded as part of a state-centred culinary establishment that was losing its significance as state restaurants were increasingly losing ground to private businesses. In contrast to state restaurants, where rankings were linked to promotions, cooks in the Glorious China believed that formal rankings were not important in the private sector. Instead, they claimed, in the private sector it was creativity, flexibility and the ability to follow the latest trends that mattered. In spite of these views, however, a number of new cooking schools were opening in the 1990s, and young cooks arriving at establishments like the Glorious China and also at privately owned restaurants were increasingly likely to have received a year or more of vocational training. The training of Chinese cooks, how this has changed over time, and how such training has shaped cooks' understandings of cuisine, are important topics demanding further research. 
Guangzhou throughout the revolutionary years, and perpetuated a sense that Guangzhou people had their own, distinctive, cuisine. After decades in which a small number of establishments had served a limited number of dishes and dimsum with few innovations, the specialities of particular restaurants in Guangzhou had become part of a common stock of knowledge among residents in the city, as had the names of famous restaurant chefs. The relative isolation of Guangzhou - certainly in contrast to neighbouring Hong Kong - helped to create discrete culinary boundaries between Guangzhou and the outside world. ${ }^{8}$

The anxieties about blurred boundaries following the increased presence of "outsiders" and "outside cuisines" in the city since the mid-1980s, as well as the intense pride in Guangzhou's culinary revival during the postMao years, need to be understood against the background of the revolutionary years, which paradoxically both impoverished Guangzhou's restaurant culture and strengthened the sense of a shared cuisine in the city. The recent interest in comparing and contrasting Cantonese with other cuisines can be understood against the backdrop of radical socialism in other ways, as well. As people have become less dependent on the work unit and reliant on a wider range of social contacts, restaurants, teahouses and other places of consumption have become crucial sites for entering into and consolidating new social and business relationships (G. Wang 2000; Thompson 1994). By the same token, knowledge about where to eat what has become a crucial form of cultural capital. Indeed, with the growing number of "outsiders" and "outside cuisines" in the city - and the greater interaction between "native" Cantonese speakers and those from elsewhere in the country and from abroad - the opportunities for and importance of consuming and comparing the cuisines of "others" have likewise increased. Other factors shaping the interest in culinary comparisons include increased opportunities for travel in China and abroad, and growing access to a variety of media connecting Guangzhou to the wider world. Through travel and the media, people in Guangzhou have become ever more aware of the global spread of Cantonese cuisine (Roberts 2002), and also of the huge popularity that Cantonese-style restaurants have enjoyed since the 1990s in cities throughout China, for example in Shanghai (Gamble 2003: 91).

In what ways, then, did Cantonese speakers in late 1990s Guangzhou distinguish Cantonese cuisine from others' foodways? Many drew attention to the consumption of particular foodstuffs and types of food. Some people emphasized the significance of leafy vegetables in the local diet, for example, while others pointed out the importance of soups. Cantonese soups - especially slowly simmered medicinal broths (C. louhfo leng tong) were regarded by people in Guangzhou as being vastly superior to the soups of other regions, and unlike other parts of China, in Guangzhou soups were eaten at the beginning of the meal. Many people I spoke to highlighted the importance of rice in the diet, and expressed surprise or

8 The "socialist culinary project" and its impact on post-Mao understandings of Guangzhou cuisine and culinary traditions are explored at greater length in Klein (forthcoming). 
horror at the thought that "Northerners" (Beifangren) - a category that could include anyone from outside Guangdong, including those from neighbouring provinces - could subsist on wheat noodles, and "foreigners" on things like bread and potatoes. In Guangzhou, noodles and dumplings made with wheat flour were generally categorized as "snacks" (C. siusihk), and were not considered filling. One acquaintance, an agricultural scientist in her forties, told me that growing up in Guangzhou she had never eaten wheat noodles at mealtimes. Recently, her teenage daughter had developed a liking for "Northern cuisine" and had actually persuaded her to prepare wheat noodles for their family's evening meal from time to time, even though she and her husband did not really feel satisfied after these meals. This anecdote not only suggests the importance of food classifications in the construction of local identities but also points to the growing influence of the younger generation over family eating habits (Jing 2000), and raises the possibility that local culinary categories might have been open to negotiation and may even have been undergoing rapid change, an issue I will return to later on in this piece.

People I met in Guangzhou pointed to the interest in food and eating itself as a defining feature of Cantonese foodways. Some highlighted the widespread popularity of dining out, and in particular what was described as the unique practice of yamchah, literally "drinking tea", or going out to drink tea and eat dimsum. ${ }^{9}$ Indeed, many of the locally recognized "signature foods" (Mintz 1996: 95) of Cantonese cuisine were derived from restaurant fare rather than home cooking, although the boundary between the two was often blurred; many people I knew would buy such foods "ready-made" at restaurants and shops to take home, serving them alongside "homemade" dishes and in some cases combining them creatively with other ingredients to make new dishes. Such signature foods included roast duck, roast goose and roast pork (chashao) - domestic ovens, with the exception of microwaves and toaster ovens, were unheard of in the city. Other famous Guangzhou specialities typical of commercial cooking were dimsum. These included classics such as prawn dumplings (xiajiao), rice flour rolls (changfen), transluscent dumplings (fenguo) and sticky-rice wraps (nuomiji), which had been developed by chefs in the grand teahouses of the Republican era on the basis of regional delicacies from Guangdong and Jiangnan (Gong 1999: 251-4; Gao and Gong 1999: 120-7). Snackshop specialities like "noodles with wonton" (hundun mian) and Cantonese-style congee (zhou) were often proudly referred to as being unique to Guangzhou. Indeed, unlike the thin, simple rice gruels often found elsewhere in China, in Guangzhou congees were elaborate, stock-based concoctions into which were mixed ingredients such as preserved duck eggs and lean pork, fish slices, frog's legs, snake meat or rare seafood. This speciality of snackshops and teahouses had become so popular that a number of up-scale "congee cities" (zhoucheng) were opened in the late 1990s. Dog meat was eaten during the colder months at restaurants and cafes specializing in hotpots, and friends pointed out to me the particular

9 See Tam $(1997 ; 2002)$ on the significance of yamchah for Hong Kong identities. 
fondness that Guangzhou people were thought to have for this delicacy, reflected in local sayings such as "When the dog meat is boiling, even the immortals cannot stand straight" (C. Gauyuhk gun saam gun, sahnsin keimwahn). One acquaintance in her 70s said that dog meat should be slowly simmered until tender, but if overcooked there is no saving it. She then added: "Northerners now also eat dog meat but they do not know how to cook it".

The quality of Cantonese food, presumed to be superior to that of other cuisines, was in fact often invoked as a distinguishing characteristic. This included the argument that, unlike Northerners, who only cared about "taste" (wei) and Westerners, who cared only about "presentation" (zaoxing), "ambiance" (qifen) and "fragrance" (xiang), Cantonese cooks not only combined "colour, fragrance, form and taste" (se xiang xing wei) when preparing a dish, but also paid careful attention to the texture or "mouth feel" (kougan) of foods. Some people claimed that Cantonese cooking was simply too complex and subtle for outsiders to learn it properly, while others argued that spoken Cantonese had a terminology for talking about food that did not exist in Mandarin. Indeed, cooks at the Glorious China invariably spoke to me in Cantonese when talking about food and cooking, even though we would otherwise often converse in a mixture of Mandarin and Cantonese, and insisted that my Cantonese must improve if I wanted to learn about Cantonese food. Spoken language and food, arguably the two most powerful markers of contemporary Cantonese identities in Guangzhou, could be articulated in such a way as to be mutually reinforcing.

The lack of food avoidances, for which the Cantonese are famous throughout China, was also mentioned by some as typical for the region, but usually in a manner that suggested that they were looking at themselves through others' eyes. "Northerners say we eat anything", was a phrase I heard on several occasions. Having said that, Cantonese speakers did emphasize the importance of trying out new foods, and saw themselves as "open-minded" (kaifang), in contrast to the "conservative" (baoshou) Northerners. In other words, for many people an interest in novelty was itself a defining characteristic of Cantonese cuisine, something I shall return to in my conclusion.

More than any other feature, however, people across the board emphasized what might be thought of as the enduring "flavouring principle" (Rozin and Rozin 2005 [1981]) of Cantonese cuisine. This was described as being "mild" (dan) or "light and mild" (qingdan), and was contrasted with "Northern cuisines", which were frequently seen to be "salty" (xian), "spicy" (la) and "heavy" (nong). As one man told me: "Our food has a balanced flavour (wohmeih), everyone can eat it. It is not stimulating (ciji) like Northern food". (The term wohmeih could mean "flavourful", but here it was being used to stress the "mildness" of Cantonese food in contrast to the "stimulating" nature of Northern cuisine.) The Cantonese ideal of "mildness" was naturalized with reference to the region's climate, soil and water. The heat in the North, many said, was dry (ganre), while Guangdong's heat was damp (shire). Because of this, 
people in Guangdong had to avoid foods that were seen to be "heating" to the body, particularly in the summer. Some people suggested that Guangdong's soil, in contrast to that of the North, was heating, while a more common argument was that it was the water in Guangdong that was heating, especially that of the Pearl River. According to one version of this argument, the leaves of a particularly heating type of cassia tree in the North of Guangdong fell into the North River before it flowed into the Pearl River. The centrality of "lightness and mildness" to definitions of Cantonese cuisine was also emphasized in scholarly works on the subject (Gao and Gong 1999: 38).

How far did food talk and the perceived characteristics of Cantonese cuisine impact on the extent to which and particular ways in which "outside" foods and techniques were incorporated into Cantonese cooking? I turn now to my discussion of continuity and innovation at the Glorious China.

\section{The Glorious China}

By Guangzhou standards the Glorious China restaurant was a reasonably large establishment. In 2000 there were 180 staff, including 65 in the serving section, 25 in the kitchen, 25 in the dimsum kitchen, 13 "runners" working between the serving section and the kitchens, and 13 dishwashers and cleaners. The restaurant was able to serve up to 600 guests on four floors of dining spaces, which included two large common dining halls and eleven private banqueting rooms. Though a "restaurant" or, literally, "winehouse" (jiulou) by name, it was often referred to in daily speech as a "teahouse" (chalou). The two terms were almost interchangeable in Guangzhou. Both referred to large, multi-storeyed establishments that were able to provide both "tea service" (chashi), i.e. tea with dimsum, and "meal service" (fanshi), i.e. rice-based meals with dishes or set banquets. ${ }^{10}$ Like many other large teahouses in the city's competitive catering trade, the Glorious China was open every day of the year from 6 a.m. until midnight, offering morning, afternoon and evening tea, and midday and evening meals.

10 In Guangzhou prior to the 1930s there appears to have been a clear-cut separation between chalou and jiulou. The former were multi-storeyed establishments serving teas and a variety of dimsum to men of different social strata, usually in common dining halls that also offered entertainment such as storytellers or blind female singers (Blofeld 1985: 57-8; Huang 1936: 9-10; Zuimian Shanren c. 1975). Jiulou, by contrast, provided set banquets and meals with dishes, alcohol and rice - and often also gambling facilities and female company - in private banqueting rooms to parties of elite male diners (Wuxing Cihangshi 1919: juan 4: 2-8; Gao and Gong 1999: 48; Gong 1999: 255). The first combined teahouse-restaurants emerged in the early 1930s (Guangzhou 1934: 250; Gao and Gong 1999: 49-53). This type of establishment seems to have become the norm in the city by the second half of the 1940s (Liao 1948: 49). At the time of my fieldwork the Glorious China formally styled itself as a jiulou, but staff and customers alike often referred to it as a chalou. Following local practice I use the terms "restaurant" and "teahouse" interchangeably in this piece. 
What set the Glorious China apart from the vast majority of eating establishments was its age. Known as an "old name in business" (laozihao), it had been founded in 1876, making it one of the oldest teahouses in the city. Like the other "old names" it had been taken over by the state in the late 1950s, a necessary but not sufficient precondition for surviving the revolutionary years. The "historic" status of the Glorious China was reinforced by its location in the northern or "upper" part of Xiguan (Shang Xiguan). Now a part of Liwan District, in late Qing and Republican times Xiguan, an area located outside the city walls until they came down in around 1920 and referred to in English as the "Western Suburb" (Rhoads 1974) or "West Gate" (Tsin 1999), had been the city's foremost trading and leisure district, and also the site of many private mansions and gardens owned by wealthy merchants. Although by the 1990s Xiguan was undergoing rapid "regeneration" (chongxiu), it still had Guangzhou's highest concentration of pre-Liberation buildings, including several teahouses and snackshops, and efforts were being made to preserve some of its historic trading streets and houses.

The customer base of the Glorious China was largely local. Many who lived in the area drank tea there on a daily basis, with their own tables and seats that fellow customers would reserve for them. Some elderly men had memories of the Glorious China going back to the 1930s and 40s. Local families drank tea there together at weekends, and some celebrated occasions such as weddings, birthdays and annual holidays in the Glorious China. Most of the banquets served on weekdays were arranged by local businesses and government bureaus.

Locals were attracted to the Glorious China for a number of different reasons. For many it was part of their daily routine, a place where they met friends or even conducted business. For many, not least the many pensioners and laid-off workers who came for morning tea, the restaurant's low prices were an important attraction. People also came for what they described as the teahouse's "traditional" flavours. Although the revolutionary years were often described as a time when "food culture" (yinshi wenhua) was virtually non-existent, still the food served at the Glorious China was seen by many staff and customers as being more "traditional" (chuantong) than that served in the restaurants that had emerged since the 1980s. This was because the cooking methods and tastes in the "old names" were perceived as having greater links with those of the Republican era, an effect of the socialist culinary project and isolation during the revolutionary years that I discussed above. People in Xiguan were often described by other Guangzhounese and by themselves as being particularly "conservative" in their tastes. The "traditional" flavours of the Glorious China were indeed praised by many of its regular customers. As one friend put it to me while we were drinking tea, invoking food memories going back to his early childhood:

After "reforms and opening up" (gaige kaifang), young people - those who are now in their forties - had never experienced truly good food. For them, anything tastes good. It is different for me. I am 71 years 
old, I know what things used to taste like. Here at the Glorious China the best things are the steamed rice flour rolls (changfen) and the steamed beef dumplings (niurou shaomai). They taste just like before the War of Resistance [against the Japanese]; the rice flour rolls are very smooth (hua). I haven't been to the Garden Hotel [one of the city's fanciest hotels, built in the 1980s] in a long time, but the last time I was there the rice flour rolls and steamed dumplings still could not match this quality.

The Glorious China's dimsum section, which was separate from the kitchen, was seen as being particularly "traditional". While many new dimsum had been introduced in the 1980s, by the late 1990s the emphasis there was on continuity rather than on innovation, on preparing wellknown snacks according to "traditional methods". The head chef of the dimsum section, Master Deng, had worked in the Glorious China for his entire career and had learned the teahouse's specialities from its previous masters.

The kitchen, which prepared banquets and dishes for midday and evening meals, was seen as being less "traditional" than the dimsum section, although it was rather conventional, doing its best to keep up with changing trends rather than shaping them. In the spring of 2000, the mealtime menu of over 200 different items included cold cuts, soups and broths, casseroles in earthenware pots, and a large number of steamed and stir-fried dishes and some deep-fried dishes. Most of the dishes on the menu could be found at similar establishments throughout the city. As at any selfrespecting Cantonese restaurant it had a cold-cut chicken as one of its signature dishes, and it adapted its menu to the different seasons, with "cooling", dishes served in the summer and a selection of hotpots served in the winter. Moreover, as had been expected of Guangzhou's Cantonese restaurants since the mid-1980s, a selection of fish, seafood and game (haixian yewei) were all sold live from tanks displayed in the restaurant's entrance hall.

Business had boomed in the 1980s and mid-1990s, but by the late 90 s the Glorious China was just breaking even, and it was facing the possibility that it might have to privatize or simply close its doors, as most other state restaurants had done in the 1990s. Managers attributed the problem in part to the growing competition with privately owned restaurants and to the broader slump in consumption of the late $90 \mathrm{~s}$, which was affecting the whole catering trade. The particular predicament for the Glorious China, as they saw it, was its local catchment area. In contrast to the Republican era, Xiguan was now largely a low income district. It had a few vibrant shopping areas and markets (including vast wholesale markets), and of course it attracted many tourists, yet during Guangzhou's post-Mao boom the centre of business activities had moved east, to Dongshan and Tianhe districts. Indeed, thanks to newly built motorways, much fine dining was moving outside of the city to the urban-rural periphery or to the smaller towns in the Pearl River Delta, which could offer larger venues, parking spaces (absolutely necessary for attracting high-level government officials 
and businesspeople) and also in many cases rare (including banned) game, gambling facilities and female company. Lacking the fame, shopping street location or picturesque, garden-style atmosphere of some other nearby restaurants, the Glorious China was having difficulty attracting tourists, shoppers or other outside customers. ${ }^{11}$ As the restaurant manager, $\mathrm{Ms} \mathrm{Li}$, put it to me: "It is not a business district and few people come from afar. [The Glorious China] is a lower-middle grade (zhong-xia dang) establishment".

The challenge, as managers described it, was to give the restaurant a more high-class look through refurbishment and by introducing new, exciting dishes that might attract more customers from a wider catchment area to their mealtime services and banquets. Since the early 1990s, in fact, the Glorious China had been busy developing its banqueting and meal services. It was in 1993 and 1994 that the establishment took its current form and size, adding two new floors and, crucially, the private banqueting or "karaoke rooms" (kalaOK tingfang). It was following this major refurbishment that the name was changed from "teahouse" to "restaurant". It was also at this time that a new head chef, Master Huang, was brought in from the private sector of the restaurant trade in an effort to make the kitchen more contemporary.

At the same time as the restaurant hoped to raise its "lower-middle" grade status, it did not want to lose the local customer base. This meant preserving the traditional style - especially during tea services - and also keeping mealtime prices as low as possible, so that even local customers who were seeking novelty might choose the Glorious China. Low prices, it was thought, were necessary also because, following the economic slump of the late 1990s, even more elite customers were seen to be looking after their expenses. These obligations to both existing and anticipated customers had a profound impact on the ways in which the menu was renewed.

\section{Regional flavours}

The most apparent "outside" influence at the Glorious China in 2000 came from Chaozhou, a city in the north-east of Guangdong which as we have seen was regarded as the centre of a unique regional cuisine, albeit one that food scholars often described as a "sub-school" of Cantonese cuisine. Indeed, the Chaozhou influence was spelled out in several places on the menu itself. For example, one section was entitled "Cantonese and Chaozhou style roast, brine-boiled and barbecued meats and fowl" (Yue Chao shao lu kao) - Chaozhou was renowned for its cold cuts that had been boiled in brine (lushui). Another section in the menu offered an assortment of "Chaozhou style soups in mini-hotpots" (C. Chiusik wohkjai). According

11 The Glorious China did run a few snack shops with better locations. Following a growing "nostalgia trend" in the city, these shops were refurbished in an antique style and were advertising their "famous traditional snacks". Indeed, the snack shops were quite successful and were helping to support the main restaurant (see Klein forthcoming). 
to the head chef, these had been introduced during the previous few years, as had dishes such as "eel wedges steamed with pickled mustard greens" (weicai zheng baishan jia) which, he argued, would be instantly recognizable to most diners as being Chaozhou dishes, even though they were not prefixed with "Chaozhou style" on the menu.

One might suggest that Chaozhou dishes were popular among diners at restaurants like the Glorious China because, like Cantonese cooking and unlike some other regional cuisines, they emphasized lightness and freshness. Indeed, Chaozhou cooks were seen to have a light touch, and the Glorious China had recently hired a native of Chaozhou to prepare steamed dishes. While this argument makes some sense, it fails to explain why a number of other outside cuisines, most notably Sichuan, had in recent years also made an impact on many Cantonese restaurants. Rather, putting Chaozhou dishes on the menu was part of the restaurant's strategy to associate itself with the higher end of the Cantonese restaurant scene.

In other words, there was a hierarchy of regional cuisines. Most topnotch hotels (binguan) in the city boasted a "Chaozhou" restaurant, and Cantonese restaurants at the higher end of the spectrum invariably had Chaozhou-style dishes on the menu. Huang explained once that: "These days, seafood restaurants calling themselves 'Chaozhou' are all very high class", adding somewhat dramatically that "It used to be that Cantonese cuisine was the leader of Guangzhou, now it is Chaozhou cuisine!'. At the lower end of the scale, Sichuan dishes such as "spicy boiled pork slices" (shuizhu roupian) (a dish that in Sichuan was usually made with beef), "the pock-marked auntie's beancurd" (mapo doufu) and "family-style doufu" (jiachang doufu) were quite common, and it was possible to find small eating places that boasted mixed Cantonese/Sichuanese menus. This hierarchy may have had something to do with the flavours attributed to these cuisines, with lighter cuisines being seen as more "refined" (jingzhi). Indeed, Cantonese restaurants at the higher end of the scale often distinguished themselves through light, delicate flavours, a prudent use of oil and spices and an emphasis on cooking techniques such as steaming and par-boiling. By contrast, the food served at low-grade Cantonese eating places was often greasy, cooked with techniques such as stir-frying and deep-frying, and it tended to be much sweeter, saltier and more pungent than "high-grade" food. In other words, the hierarchy of regional cuisines had something to do with the flavours attributed to them and the ways these were ordered according to pre-existing Cantonese norms of refinement.

Yet this explanation is incomplete insofar as it could not tell us why Chaozhou cuisine had become popular at that particular time. Master Huang and the other cooks at the Glorious China in fact pointed to nonculinary factors, to the ways in which places and people were hierarchized in contemporary China according to a scale from "backwardness" to "advancement" (Liu 2000). They told me that Chaozhou had previously been poor, and explained the recent pull of Chaozhou cooking in terms of the city's economic ascent in the 1990s. Indeed, Chaozhou people were often described (albeit somewhat ambiguously) by Cantonese speakers in 
Guangzhou as being "clever" (C. lek) and "good at making money" (C. hou wandou chin). ${ }^{12}$ By contrast, Sichuan, Hunan and other provinces in the interior were generally regarded as being "backward" (luohou) and people from these regions were seen as "migrant workers" (mingong). That the tendency for high-end Cantonese restaurants to draw on Chaozhou cooking and for low-end restaurants to borrow from Sichuan cooking was not simply about "flavour" but also about "taste" as a social discriminator (Bourdieu 1984) will emerge more clearly below, where I show that the Glorious China had in fact adopted several heavy and spicy dishes, but by way of Hong Kong rather than Sichuan.

\section{Hong Kong's impact}

The fact that people in Guangzhou were able to talk about Guangzhou and Guangdong cuisine as being one and the same thing seems based on the notion that Guangzhou was at its centre, a notion that drew on longstanding associations between regional cooking styles and the occupational cooks and restaurants of major cities (Anderson 1988: 194; Chang 1977: 14; Sabban 1999). However, the assumption that Guangzhou is at the centre of "Cantonese cuisine" is increasingly problematic at a time when Hong Kong has emerged as a major producer of transnational culture (Watson 1997; Mintz and Tan 2001; Gold 1993), and when Guangzhou, Hong Kong and the Pearl River Delta area may be merging into a single southern Chinese "megacity" of some 50 million or more people (Castells 1996: 403-10; Guldin 1995: 113-4).

The profound impact of Hong Kong on Cantonese restaurant culture in Guangzhou can hardly be denied. Since the early 1980s, Hong Kong had been both a model for emulation among restaurateurs and cooks, and also a crucial source of investment in the city's restaurant and hotel industries (Gao and Gong 1999: 61-3; Vogel 1989: 202-3). Hundreds of Hong Kongstyle dimsum and dishes were enthusiastically taken up by Guangzhou chefs in the 1980s, and new types of eating establishments were imported from Hong Kong. These included "tea cafes" (chacanting) and "streetside cooked food stalls" (C. daaihpaaidong) (Wu 2001). The latter term once referred to a specific type of open-air establishment, but by the late 1990s it had come to be used for any restaurant which was seen to cater to popular or "mass" (dazhonghua) tastes, and which did not provide tea and dimsum service.

New serving styles were also introduced from Hong Kong. Customers and employees described how, prior to the mid-1980s, the mostly male

12 The argument that Chaozhou cooking was regarded as a "leading cuisine" in Guangzhou because of Chaozhou's associations with economic success receives some support from research carried out in Hong Kong. Sidney Cheung discusses an unpublished study by Lee (1997), in which it is argued that Chaozhou cuisine became popular there because "the success stories about the hardworking Chiu Chow [Chaozhou] people were well accepted by the Hong Kong public and they accepted an 'upgraded' Chiu Chow cuisine serving as a metaphor for upward social mobility" (Cheung 2002: 101). 
waiting staff in the Glorious China and other Guangzhou teahouses would walk around the dining rooms shouting out the wares they had in the huge baskets they held in their hands, supported by straps hanging from their necks. Later, another waiter would add together the empty plates and steamers and then "call out the bill" (jiaodan) to the staff at the counter, using a coded language to distinguish different groups of customers. Even during the Cultural Revolution, when at-the-table service was abolished, "calling out the bill" was not. From the early 1980s, dimsum were placed, Hong Kong-style, on trolleys and wheeled around to customers, usually by female waiting staff. ${ }^{13}$ Each party received a card which was stamped by the waitress every time a snack was chosen and quietly added up as one finished.

However, if the influence of Chaozhou was explicitly stated on the menu, little attention was drawn to the much more pervasive impact of Hong Kong. This is perhaps surprising given my argument that upwardly mobile cooks and restaurants wished to be associated with economically successful, "advanced" places. Indeed, only five or six years earlier, I was told, a number of dishes on the Glorious China's menu would have been prefixed with the words "Hong Kong style" (Gangshi). By the late 1990s, however, Guangzhou food journalists, food scholars and cookbook authors were proudly declaring Guangzhou's increasing culinary independence from Hong Kong, and presenting Guangzhou as having reclaimed its position at the centre of Cantonese cuisine (Shi 1997; Gao and Gong 1999; Chen 1997; Liang and Liao 2000).

Unlike these writers, cooks at the Glorious China did not deny the ongoing relevance of Hong Kong cooking. Indeed, they claimed to take no interest in locally published trade journals like Guide to Delicacy (Meishi Daobao) and Guangdong Cooking (Guangdong Pengren), even though copies of the latter were regularly dispatched to the kitchen by the Glorious China head office. Instead, to keep up with the latest trends they read Hong Kong food magazines such as Food World (Yinshi Tiandi) and even watched Hong Kong television cooking programmes aimed at domestic cooks, in particular the show that featured Mrs. Fong (C. Fong Taai), by far the most popular Hong Kong television chef in Guangzhou at that time. Crucially, cooks argued that Hong Kong cooking was more outwardlooking than Guangzhou cuisine. As the number three cook at the Glorious China put it, "Hong Kong cooking is more advanced than here. There they combine Chinese and foreign styles much more than we do". Master Huang even suggested that the impact of "foreign" cuisines - and even that of some Chinese regional styles - on Cantonese cooking in Guangzhou had more to do with the mediation of Hong Kong than it did with the presence of these outside restaurants in Guangzhou:

13 With the rapid development of a male-centred banqueting culture in the 1980s and 90 s, front of house (loumian, literally "face of the house") staff were increasingly likely to be young women, reflecting a broader feminization of many parts of urban China's growing service sector (Z. Wang 2000). 
There are new dishes coming out of Guangdong every year. Now the influences are from "local snacks" (difang xiaoshi) in Guangdong, minority areas in Guangxi and Yunnan's Xishuangbanna, from Southeast Asia, especially Vietnam - all tropical areas. Between '86 and '95 most of the influences came from the West - France, England, the United States. By "96 it had changed. "Local snacks" became more important. It was the same in Hong Kong. Actually, we follow Hong Kong. Guangdong cooks are influenced by Hong Kong.

At the same time that Hong Kong's influence remained great, however, Guangzhou chefs were arguably becoming increasingly confident, and it might be suggested that Hong Kong's diminishing attraction for diners enabled chefs to appropriate Hong Kong styles with greater selectivity and creativity. All of this can be illustrated with a look at "Cantonese nouvelle cuisine".

\section{From Hong Kong style Cantonese cuisine to Cantonese nouvelle cuisine}

The names "new wave" (xinchao) or "new school" (xinpai) Cantonese cuisine, what I translate here as Cantonese nouvelle cuisine, first appeared in Hong Kong in the 1970s to refer to the internationalized cooking and serving styles emerging in some of the city's up-market restaurants (Cheung 2002: 105-6). In Guangzhou, the term was for a long time used more or less synonymously with "Hong Kong-style Cantonese cuisine" (Gao and Gong 1999: 216). Master Huang explained to me that the style was introduced to Guangzhou in the mid-1980s by the Hong Kong chefs who had been hired to run the Cantonese kitchens in the new international joint-venture hotels. By 1986 or 1987, the local cooks who worked under the Hong Kong masters found employment in other restaurants and introduced the new techniques there. More recently, however, Cantonese nouvelle cuisine was seen in Guangzhou as having become increasingly autonomous from Hong Kong. This was particularly emphasized by food writers. However, even Huang claimed that, by the late 1990s, Guangzhou's cooks had not only mastered the nouvelle cuisine but they had even surpassed their colleagues in Hong Kong in the new styles. This was because, he argued, the Guangzhou cooks had much "deeper roots in Chinese traditional cooking methods", a reference perhaps to the training he and others had received at cooking academies.

Among cooks and food writers in Guangzhou, Cantonese nouvelle cuisine was sometimes described as a movement led by specific chefs, akin perhaps to certain textbook definitions of French nouvelle cuisine (Larousse Gastronomique 1988: 732). More often, though, the term was used in a more vague sense to sum up what were regarded as the most important trends in up-market Cantonese cooking of the past few decades. While descriptions of the new cuisine in Guangzhou varied a great deal, most emphasized that lightness and freshness were key characteristics, claiming that these were even more important than in "traditional" 
Cantonese cooking. Further, all stressed the use of non-Cantonese ingredients and techniques. In this sense it was typical of Jack Goody's concept of an haute cuisine, which displays the cosmopolitanism of its elite consumers through the breadth of its influences (Goody 1982: 105; Cheung 2002: 106).

As a marker of distinction, Cantonese nouvelle cuisine helped rank not only consumers but also establishments and staff. Among cooks in the Glorious China, a Cantonese restaurant and its head chef were described as "high grade" only to the extent that they had embraced the new styles. As with Chaozhou-style dishes, introducing Cantonese nouvelle cuisine dishes to the Glorious China menu was an important part of its strategy to become a "high grade" restaurant and attract more customers at mealtimes, in particular more high-paying customers from outside the immediate neighbourhood. Master Huang carefully selected those techniques and dishes from nouvelle cuisine which could be adapted to the needs of the restaurant. One nouvelle introduction to the Glorious China's menu was "country-style dace ${ }^{14}$ stuffed with minced pork" (jiaxiang niang lingyu), a classic from nearby Shunde which they had "improved" (gailiang) by adding Western-style barbecue sauce (shaokaozhi) to the stuffing. Huang explained that this dish reflected the nouvelle cuisine's emphases on local country styles and on foreign "mixed" or "ready made" sauces (fuhejiang), like barbecue sauce and mayonnaise or salad cream (C. saleutjeung).

According to Huang, nouvelle cuisine chefs also used methods that combined the flavours of several ingredients in one dish. One of the most popular methods was kao (C. haau), a kind of braising that Huang claimed was an adaptation of a French method. It involved pre-cooking two or more main ingredients, layering these in an earthenware pot, and then simmering them under a lid. For Huang, the advantage was that one could combine small quantities of expensive ingredients, such as scallops or shark's fin, with larger quantities of cheap ones, such as radishes, in such a way that they would "mutually absorb each other's flavours", as he put it. This would have been unheard of in the traditional Cantonese kitchen, he argued. However, kao had become a popular cooking method in the late 1990s, he told me, "now that people don't have so much money".

Cooks at the Glorious China took a very pragmatic approach to the nouvelle cuisine, emphasizing those aspects which could be useful for the restaurant. Introducing novel methods from nouvelle cuisine or the Chaozhou kitchen was above all a way of not falling too far down in the hierarchy of eating places, and for the cooks it was a means of keeping up with colleagues in the more up-market establishments. For Huang, using methods which allowed one to combine cheap and expensive ingredients in one dish was a means to allow customers to sample the latest trends at affordable prices.

In the literature on nouvelle cuisine, the practice of combining cheap and expensive ingredients in one dish was often referred to as "coarse materials,

14 The lingyu (Circhina molitorella), translated here as "dace", is a freshwater flatfish that is common in the Pearl River Delta area. 
refined preparation" (culiao jingzhi) - a term that had also been used in revolutionary-era cookbooks in an attempt to create a socialist, egalitarian Cantonese cuisine. This practice was now widespread in Guangzhou restaurants, ironically in particular in the city's most expensive seafood palaces, where sweet potato leaves (fanshuye) and other foods that were widely regarded as "famine foods" had recently become popular. These dishes did not find their way into the Glorious China, however, whose regulars were mostly of rather modest means and who presumably had not developed a nostalgia for such foods. Huang and the Glorious China managers only introduced those nouvelle dishes that they thought would find a market.

\section{Conclusion}

According to Master Huang, a core feature of Cantonese cuisine was its ability to adopt new foodstuffs and techniques. For him, the Mao years had been particularly detrimental to Guangzhou's food culture because of the lack of innovation due to the non-existence of competition between restaurants and to the city's isolation from the wider world of goods and flavours. At the same time, however, Huang also presented Cantonese cuisine as having a certain essence, expressed in ideas of lightness and freshness and of seeking the "original" or "natural" flavour of an ingredient. He sometimes summed up these two aspects of Cantonese cuisine with the saying "to change countless times while remaining true to its principles" (wan bian bu li qi zong). While few people I met had developed theories of cuisine as coherent as those of Master Huang, both notions of Cantonese cuisine were widespread at the time of my fieldwork.

Huang's theory, not dissimilar to some of the more structuralist academic theories of cuisine (e.g. Ashkenazi and Jacob 2000), was of course unable to account for the historical contingency of specific innovations. Why these particular influences at this particular time? When considering this, the performed aspect of a cuisine become important, that is its expressed use as a symbol of identifications along the lines of locality, region or class. In this paper I have given examples of how the menu at the Glorious China was shaped both by attempts at upward mobility and by local, even neighbourhood-specific, notions of "traditional" flavours. We have also seen how specific borrowings, and the ways these were presented in menus, were shaped by new hierarchies of place and place-based ethnicities and by the ongoing rivalry between two centres of Cantonese cuisine. These examples suggest that "Cantonese" cuisine does not simply reflect any pre-existing or stable community. Rather, it is a medium through which communities and their relation to one another are defined and negotiated.

In addition to not being able to account for specific changes, the idea of change within continuity denies the possibility that the "outside" may in fact have profound effects on basic flavours and cooking techniques, rather than being shaped or even absorbed by the latter. Indeed, many of the techniques and dishes that Huang proudly presented to me as examples of 
"nouvelle cuisine" at the Glorious China could hardly be described as "light" or as seeking the "original" flavours in ingredients. Nor could this be said of the growing use of chillies and other spices, especially at the lower end of the Cantonese restaurant trade. We are left, then, with a paradox: the notion that Cantonese cuisine in Guangzhou was able to change while at the same time remaining true to itself persisted, regardless of the changes going on to the supposedly basic flavour principles and to the communities to which they were seen to belong. But perhaps it is this very paradox that is the strength of Cantonese cuisine? That is, local discourse on food maintained the regional cuisine not only by sustaining shared understandings and ensuring the production of goods, but also through the articulation of ideas which repeatedly contrasted Cantonese and outside cuisines. Through the discursive creation of a cuisine that could both embrace and deny change, global and transregional forces were transformed from potential threats to Cantonese cuisine in Guangzhou, and became resources for its renewal.

\section{References}

Amit, Vered. 2002. "Reconceptualizing community", in Vered Amit (ed.), Realizing Community: Concepts, Social Relationships and Sentiments. London and New York: Routledge, 1-20.

Anderson, Benedict. 1991. Imagined Communities: Reflections on the Origin and Spread of Nationalism (revised edition). London: Verso.

Anderson, E.N. 1988. The Food of China. New Haven and London: Yale University Press.

Appadurai, Arjun. 1988. "How to make a national cuisine: cookbooks in contemporary India", Comparative Studies in Society and History 30, 3-24.

Ashkenazi, Michael and Jean Jacob. 2000. The Essence of Japanese Cuisine: An Essay on Food and Culture. Richmond, Surrey: Curzon Press.

Avieli, Nir. 2005. "Roasted pigs and bao dumplings: festive food and imagined transnational identity in Chinese-Vietnamese festivals", Asia Pacific Viewpoint 46/3, 281-93.

Belasco, Warren. 2004 [1999]. "Food and the counterculture: a story of bread and politics", in James L. Watson and Melissa L. Caldwell (eds), The Cultural Politics of Food and Eating: A Reader. Oxford: Blackwell, 217-34. [Originally published in Raymond Grew (ed.), Food in Global History. Boulder: Westview Press, 273-92.]

Blofeld, John. 1985. The Chinese Art of Tea. London: George Allen \& Unwin.

Bourdieu, Pierre. 1984. Distinction: A Social Critique of the Judgement of Taste (trans. Richard Nice). London and New York: Routledge.

Castells, Manuel. 1996. The Rise of the Network Society. Oxford: Blackwell.

Chang, K.C. 1977. "Introduction", in K.C. Chang (ed.), Food in Chinese Culture: Anthropological and Historical Perspectives. New Haven and London: Yale University Press, 1-21.

Chen Qingqian. 1997. Xinpai Yuecai (New School Cantonese Cuisine). Guangzhou: Guangdong Lüyou Chubanshe.

Cheung, Sidney C.H. 2002. "Food and cuisine in a changing society: Hong Kong", in David Y.H. Wu and Sidney C.H. Cheung (eds), The Globalization of Chinese Food. Honolulu: University of Hawai'i Press, 100-12. 
Chua Beng Huat and Ananda Rajah. 2001. "Hybridity, ethnicity and food in Singapore", in David Y.H. Wu and Tan Chee-beng (eds), Changing Chinese Foodways in Asia. Hong Kong: The Chinese University Press, 161-97.

Cohen, Anthony P. 1985. The Symbolic Construction of Community. London and New York: Tavistock Publications.

Croll, Elisabeth. 1983. The Family Rice Bowl: Food and the Domestic Economy in China. London: Zed Press.

Csergo, Julia. 1999. "The emergence of regional cuisines", in Jean-Louis Flandrin and Massimo Montanari (eds), Food: A Culinary History from Antiquity to the Present. New York: Columbia University Press (English ed. Albert Sonnenfeld), $500-15$.

Cwiertka, Katarzyna J. 2003. "Eating the world: restaurant culture in early twentieth century Japan", European Journal of East Asian Studies 2/1, 89-116.

Cwiertka, Katarzyna J. 2006. Modern Japanese Cuisine: Food, Power and National Identity. London: Reaktion Books.

Davis, Deborah S. 2000. "Introduction: a revolution in consumption", in Deborah S. Davis (ed.), The Consumer Revolution in Urban China. Berkeley: University of California Press, 1-22.

Deng Duanben, Ou Annian, Jiang Lifu and Mai Guoliang. 1997. Lingnan Zhanggu (Anecdotes from Lingnan), two volumes. Guangzhou: Guangdong Lüyou Chubanshe.

Faure, David. 1996. "History and culture", in Brian Hook (ed.), Guangdong: China's Promised Land. Hong Kong: Oxford University Press, 1-29.

Friedman, Edward. 1994. "Reconstructing China's national identity: a southern alternative to Mao era anti-imperialism", The Journal of Asian Studies, 53/1, 67-91.

Gamble, Jos. 2003. Shanghai in Transition: Changing Perspectives and Social Contours of a Chinese Metropolis. London and New York: RoutledgeCurzon.

Gao Xuzheng and Gong Bohong. 1999. Guangzhou Meishi (Guangzhou Delicacies). Guangzhou: Guangdong Sheng Ditu Chubanshe.

Gold, Thomas B. 1993. "Go with your feelings: Hong Kong and Taiwan popular culture in Greater China", The China Quarterly 136, 907-25.

Gong Bohong. 1999. Guangfu Wenhua Yuanliu (Origins and Development of Cantonese Culture). Guangzhou: Guangdong Gaodeng Jiaoyu Chubanshe.

Goodman, Bryna. 1995. Native Place, City, and Nation: Regional Networks and Identities in Shanghai, 1853-1937. Berkeley: University of California Press.

Goody, Jack. 1982. Cooking, Cuisine and Class: A Study in Comparative Sociology. Cambridge: Cambridge University Press.

Guangzhou Nianjian Bianzuan Weiyuanhui (ed.). 1988. Guangzhou Nianjian (Guangzhou Yearbook). Guangzhou: Guangzhou Nianjian Chubanshe.

Guangzhou Nianjian Bianzuan Weiyuanhui (ed.). 1999. Guangzhou Nianjian (Guangzhou Yearbook). Guangzhou: Guangzhou Nianjian Chubanshe.

Guangzhou Shizhengfu. 1934. Guangzhou Zhinan (Guangzhou Guide). Guangzhou: Guangzhou Shizhengfu.

Guldin, Gregory Eliyu. 1995. "Toward a greater Guangdong: Hong Kong's sociocultural impact on the Pearl River Delta and beyond", in Reginald YinWang Kwok and Alvin Y. So (eds), The Hong Kong-Guangdong Link: Partnership in Flux. Armonk: M. E. Sharpe, 89-118.

Han Boquan. 1992. "Guangdong juan" (Guangdong), in Lu Kecai (ed.), Zhonghua Minzu Yinshi Fengsu Daguan (Survey of the Culinary Customs of the Chinese Nation). Beijing: Shijie Zhishi Chubanshe, 338-44. 
Ho, Virgil Kit-yiu. 1991. "The limits of hatred: popular attitudes towards the West in Republican Canton", East Asian History 2, 87-104.

Hobsbawm, Eric and Terence Ranger (eds). 1983. The Invention of Tradition. Cambridge: Cambridge University Press.

Hsu, Vera and Francis L.K. Hsu. 1977. "Modern China: North", in K.C. Chang (ed.), Food in Chinese Culture: Anthropological and Historical Perspectives. New Haven and London: Yale University Press, 295-316.

Huang Minghui. 1936. Guangzhou ji Xianggang (Guangzhou and Hong Kong). Shanghai: Xin Shengming Shuju.

Jing, Jun. 2000. Feeding China's Little Emperors: Food, Children, and Social Change. Stanford: Stanford University Press.

Klein, Jakob A. 2004. Reinventing the Traditional Guangzhou Teahouse: Caterers, Customers and Cooks in Post-Socialist Urban South China. Unpublished PhD thesis, University of London.

Klein, Jakob. 2006. "Changing tastes in Guangzhou: restaurant writings in the late 1990s", in Kevin Latham, Stuart Thompson and Jakob Klein (eds), Consuming China: Approaches to Cultural Change in Contemporary China. London and New York: Routledge, 104-20.

Klein, Jakob A. Forthcoming. "'For eating, it's Guangzhou': regional culinary traditions and Chinese socialism", in Harry West and Parvathi Raman (eds), Enduring Socialism: Explorations of Revolution and Transformation, Restoration and Continuation. New York and Oxford: Berghahn Books.

Larousse Gastronomique (English edition). 1988. London: Paul Hamlyn.

Latham, Kevin. 1996. Cantonese Opera in Hong Kong: An Anthropological Investigation of Cultural Practices of Appreciation and Performance in the Early 1990s. Unpublished PhD thesis, University of London.

Lee, Wai Yee. 1997. Food and Ethnicity: A Study of Eating Habits among Chiu Chow People in Hong Kong. Unpublished M.Phil. thesis, Department of Anthropology, The Chinese University of Hong Kong.

Li Xiusong. 1995. "Guangdong cai" (Cantonese cuisine), in Zhongguo Pengren Baike Quanshu Bianweihui and Zhongguo a Baike Quanshu Bianjibu (eds), Zhongguo Pengren Baike Quanshu (Encyclopedia of Chinese Cooking). Beijing: Zhongguo Da Baike Quanshu Chubanshe.

Liang Chang and Liao Lixiang. 2000. Xinchao Yuecai (New Wave Cantonese Cuisine, 2 vols). Guangzhou: Guangdong Keji Chubanshe.

Liao Shulun (ed.). 1948. Guangzhou Daguan (Grand Spectacle of Guangzhou). Guangzhou: Tiannan Chubanshe.

Liu Manqiu. 1999. Guangzhou Diyi Jia: Guangzhou Jiujia Jian Dian Liushi Zhounian (The Foremost House in Guangzhou: The Sixtieth Anniversary of the Establishment of the Guangzhou Restaurant). Guangzhou: Guangdong Gaodeng Jiaoyu Chubanshe.

Liu, Xin. 2000. In One's Own Shadow: An Ethnographic Account of the Condition of Post-Reform Rural China. Berkeley: University of California Press.

Miles, Steven B. 2006. The Sea of Learning: Mobility and Identity in Nineteenth-Century Guangzhou. Cambridge, MA and London: Harvard University Asia Center.

Mintz, Sidney W. 2002. "Food and eating: some persisting questions", in Warren Belasco and Philip Scranton (eds), Food Nations: Selling Taste in Consumer Societies. New York and London: Routledge, $24-47$.

Mintz, Sidney W. 1996. Tasting Food, Tasting Freedom: Excursions into Eating, Culture, and the Past. Boston: Beacon Press. 
Mintz, Sidney W. and Chee Beng Tan. 2001. "Bean-curd consumption in Hong Kong", Ethnology 40/2, 113-28.

Rhoads, Edward. 1974. "Merchant associations in Canton, 1895-1911", in Mark Elvin and G. William Skinner (eds), The Chinese City Between Two Worlds. Stanford: Stanford University Press, 97-117.

Roberts, J.A.G. 2002. China to Chinatown: Chinese Food in the West. London: Reaktion Books.

Rozin, Elizabeth and Paul Rozin. 2005 [1981]. "Culinary themes and variations", in Carolyn Korsmeyer (ed.), The Taste Culture Reader: Experiencing Food and Drink. Oxford: Berg, 34-41. [Originally published in Natural History February 1981, 6-14.]

Sabban, Françoise. 1999. "China: eating and cooking", in Alan Davidson (ed.), The Oxford Companion to Food. Oxford: Oxford University Press, 171-73.

Schintz, Alfred. 1989. Cities in China. Berlin: Gebrüder Borntraeger.

Shen Hongfei. 2000. Xieshi zhuyi (Gastronomism). Chengdu: Sichuan Wenyi Chubanshe.

Shi Peilin. 1997. "Guangzhou shisi gaobie Gangchu" (Guangzhou restaurants bid farewell to Hong Kong chefs), Yangcheng Wanbao (Yangcheng Evening News), 29 July.

Short, Frances. 2006. Kitchen Secrets: The Meaning of Cooking in Everyday Life. Oxford: Berg.

Simoons, Frederick J. 1991. Food in China: A Cultural and Historical Inquiry. Boca Raton: CRC Press.

Siu, Helen. 2002. "Redefining the market town through festivals in south China", in David Faure and Tao Tao Liu (eds), Town and Country in China: Identity and Perception. Houndmills: Palgrave, 233-49.

Snow, Don. 2004. Cantonese as Written Language: The Growth of a Written Chinese Vernacular. Hong Kong: Hong Kong University Press.

Sutton, David E. 2001. Remembrance of Repasts: An Anthropology of Food and Memory. Oxford: Berg.

Tam, Siumi Maria. 1997. "Eating metropolitaneity: Hong Kong identity in yumcha", The Australian Journal of Anthropology 8/3, 291-306.

Tam, Siumi Maria. 2002. "Heunggongyan forever: immigrant life and Hong Kong style yumcha in Australia", in David Y.H. Wu and Sidney C.H. Cheung (eds), The Globalization of Chinese Food. Honolulu: University of Hawai'i Press, 131-51.

Tang Zhengchang. 1999. "Yuecai pian" (A note on Cantonese cuisine), in his Zhongguo Yinshi Wenhua Sanlun (Essays on Chinese Culinary Culture). Tapei: Taiwan Shangwu Yinshuguan.

Thompson, Stuart. 1994. "Riz de passage? Life bytes and alimentary practices", China Now 149, 10-12.

Tsin, Michael. 2000. "Canton remapped”, in Joseph W. Esherick (ed.), Remaking the Chinese City: Modernity and National Identity, 1900-1950. Honolulu: University of Hawai'i Press, 19-29.

Vogel, Ezra. 1989. One Step Ahead in China: Guangdong under Reform. Cambridge, MA: Harvard University Press.

Wang, Gan. 2000. "Cultivating friendship through bowling in Shenzhen", in Deborah S. Davis (ed.), The Consumer Revolution in Urban China. Berkeley: University of California Press, 250-67.

Wang, Shaoguang. 1995. "The politics of private time: changing leisure patterns in urban China", in Deborah S. Davis et al. (eds), Urban Spaces in Contemporary 
China: The Potential for Autonomy and Community in Post-Mao China. Washington, D.C.: Woodrow Wilson Press; and Cambridge: Cambridge University Press, 149-72.

Wang Wenyuan. 1927. "Guangzhou de chadian” (Guangzhou's tea snacks), Yusi (Threads of Words) 126, 24-26.

Wang, Zheng. 2000. “Gender, employment and women's resistance”, in Elizabeth J. Perry and Mark Selden (eds), Chinese Society: Change, Conflict and Resistance. London and New York: Routledge, 62-82.

Watson, James L. 1997. "McDonald's in Hong Kong: consumerism, dietary change, and the rise of a children's culture", in James L. Watson (ed.), Golden Arches East: McDonald's in East Asia. Stanford: Stanford University Press, 77-109.

Wilk, Richard R. 2002. "Food and nationalism: the origins of "Belizean food"', in Warren Belasco and Philip Scranton (eds), Food Nations: Selling Taste in Consumer Societies. New York and London: Routledge, 67-89.

Wilk, Richard. 2006a. "From wild weeds to artisanal cheese", in Richard Wilk (ed.), Fast Food, Slow Food: The Cultural Economy of the Global Food System. Lanham, MD: Altamira Press, 13-27.

Wilk, Richard. 2006b. Home Cooking in the Global Village: Caribbean Food from Buccaneers to Ecotourists. Oxford: Berg.

Wu, David Y.H. 2001. "Chinese café in Hong Kong”, in David Y.H. Wu and Tan Chee-beng (eds), Changing Chinese Foodways in Asia. Hong Kong: The Chinese University Press, 71-80.

Wuxing Cihangshi. 1919. Guangzhou Zhinan (Guangzhou Guide). Shanghai: Xinhua Shuju.

Yan, Yunxiang. 2000. "Of hamburger and social space: consuming McDonald's in Beijing", in Deborah S. Davis (ed.), The Consumer Revolution in Urban China. Berkeley: University of California Press, 201-25.

Ye Chunsheng. 1992. "Rong Zhong Xi yu yi lu, ji shi yi yu yi tang - Guangzhou chalou wenhua yanjiu" (Mixing Chinese and Western in one oven, combining food and art under one roof: a study of Guangzhou's teahouse culture), in Shanghai Minjian Wenyijia Xiehui (ed.), Zhongguo Minjian Wenhua (Chinese Folk Culture), Vol 8. Shanghai: Xuelin chubanshe.

Zhongguo Caipu Bianxiezu (ed.). 1976. Zhongguo Caipu (Guangdong) (The China Cookbook: Guangdong). S.1.: Zhongguo Caizheng Jingji Chubanshe.

Zhu Xiaodan (gen. ed.). 1999-2000. Ke'ai de Guangzhou Congshu (Beloved Guangzhou Series), six volumes. Guangzhou: Guangdong Sheng Ditu Chubanshe.

Zuimian Shanren. c. 1975. "Banmangmei chalou duqu" (Fake blind girl sings in teahouse), in his Guangdong Heimu Daguan (Grand Spectacle of the Scandalous Side of Guangdong). Facsimile of early 1920s edition. 


\section{Glossary: Chinese characters for selected terms and sayings}

Cheun bin chau leih hah saamleih (C.)

Chiusik wohkjai (C.)

culiao jingzhi

fuhejiang

fushi

Gauyuhk gun saam gun, sahnsin keimwahn (C.)

haau (C.)

jiaxiang niang lingyu

kougan

laozihao

louhfo leng tong (C.)

lushui

qingdan

saleutjeung (C.)

Sang chung suhk syuhn bun bihng gauchoi (C.) se xiang xing wei

shaokaozhi

siusihk (C.)

wan bian bu li qi zong

weicai zheng baishan jia

wohmeih (C.)

yamchah (C.)

zhushi

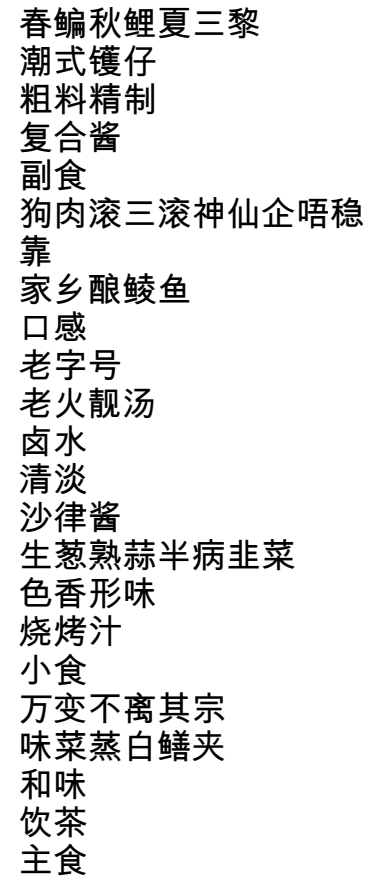

